\title{
Introduction: some new methods in regional science
}

\author{
Danny Czamanski · Henk Folmer
}

Published online: 23 June 2010

(C) The Author(s) 2010. This article is published with open access at Springerlink.com

\section{Introduction}

Ever since Kuhn (1962), questions concerning the growth of scientific knowledge have focused on the role of changing paradigms. Postmodernism notwithstanding, the evolution of science, like the evolution of all open-ended systems, is the result of self-organizing processes. The typical dynamics consists of the performance of research, the critical examination of its results by peers and the publication of those results that withstand peer reviews. The practical essence of such self-organization in science is the getting together of scholars at workshops and conferences and the resulting discourse that from time to time shifts attention to new phenomena, to new ways of examining them and to publications that document them. The crucial steps in this regard are:

- identification of new research themes,

- development of new concepts and theories, and

- development of new methods.

Occasionally, the self-organizing dynamics of scientific progress results in fundamental shifts that involve all these elements. More often, progress occurs as a result of changes in only one particular element. When such change occurs, the peculiarities of a typical step can be analyzed without the risk of confusion with other steps.

While scientific progress is often hindered by lack of sufficient financial support, lack of interaction among scholars can be equally or even more damaging. Despite

D. Czamanski $(\bowtie)$

Complex City Research Lab, Faculty of Architecture and Town Planning,

Technion-Israel Institute of Technology, Haifa, Israel

e-mail: danny@czamanski.com

H. Folmer

Department of Spatial Sciences, University of Groningen, Groningen, The Netherlands 
technological developments, such as electronic publishing and Internet that facilitate interactions, face-to-face meetings remain a crucial form of interaction. These types of interactions are needed at virtually all stages of scientific development. It is particularly needed at the early stages of development when new themes, concepts and methods are emerging in efforts to separate the wheat from the chaff and to boost potential new developments. Of course, nowadays the number of conferences that offer opportunities for interaction is overwhelming. However, many large-scale conferences are not suitable for intensive interaction and in-depth review of new themes, theories or methods. Small workshops that focus on a limited number of topics and that offer ample opportunities for discussion play a critical role.

The Israeli-Dutch Regional Science workshops that take place every 2 years serve this purpose. The last one in the series was held at Jerusalem in November 2008. It focused on new methods. The papers in this special issue are based on presentations and discussions at this workshop and focus on four groups of subjects.

\section{Transportation}

Transportation issues have been of concern to Regional Science since its inception. Issues concerning the nature of distance, accessibility, and the impact of technological innovation on spatial behavior and therefore on the spatial distribution of activities have been at the forefront. Until quite recently, empirical studies of accessibility and its impact on spatial behavior and the resulting arrangement of activities have been based on spatially crude, averaged data. As accessibility to spatially detailed data is becoming increasingly available and inexpensive, scholars are reaching beyond spatially averaged data and stylized facts and there is intensive reexamination of concepts and models. The following papers are in this category.

Benenson, Martens, Rofe and Kwartler present a novel measure of urban accessibility by public transportation and private cars. It presents an ArcGis extension for estimating car-based and transit-based accessibility to employment and other land uses. The resulting, spatially detailed measurements in Tel Aviv stand in contrast to other studies of urban accessibility. In particular, gaps between car-based and transitbased accessibility are found to be larger than those identified in previous studies. The results point to the need for detailed policies that address spatial variations.

The paper by Shiftan and Ben-Akiva is also concerned with realism in modeling. It presents an activity-based model that captures key behavioral aspects and policy sensitivities, while remaining practical with reasonable requirements of computational resources. Based on an application to, among others Tel Aviv, the authors indicate that it is possible to achieve a high degree of behavioral realism and policy sensitivity with a reasonable level of model complexity.

The third paper, by Thissen, Limtanakool and Hilbers, is concerned with the direct and particularly indirect effect of congestion charges on agglomeration. Unlike most previous studies, which dealt with a single region, the authors analyze multiregional impacts. Because of the difficulty of directly assessing agglomeration effects of congestion charges by way of a spatial computable general equilibrium (SCGE) approach, 
the paper applies a methodology based on a multiplier derived from a SCGE model with an agglomeration-neutral redistribution effect.

\section{Housing market analysis}

A key issue in housing market analysis is the understanding of its dynamics. One aspect is mobility among different states of the housing market, e.g., among price classes. Since mobility in the housing market typically involves movement from one state to another, vacancy chain analysis has become an important technique to analyze mobility in the housing market. Another key issue relates to the the long-run relationships and short-run dynamics between a housing market characteristic, e.g., prices or building volumes, and their determinants such as demographic developments. Cointegration and error correction models have been developed to analyze such relationships (see e.g., Greene 2004)

The first issue is addressed by Ben-Shahar and Sulganik who explore housing market vacancy chains and mobility among states of tenure modes and price classes. By focusing on intra- and inter-state mobility, they calculate "multiplier effects".

The second issue is addressed by van der Vlist together with the editors of this special issue. They study housing price dynamics as a result of a demand shock that the Haifa market experienced following the massive immigration from the former Soviet Union. Based on transactions data, they analyze the time-dependent behavior of prices and some factors responsible for the observed pattern by means of an error correction model taking into account spatial spillovers.

\section{Capital markets}

Macro models of regional economic performance suffer from the absence of reliable estimates of capital stocks. The extant methods to overcome the situation apportion various estimates of national capital stocks to regions or estimate the stock directly by means of a perpetual inventory method. Estimates of regional investments are applied to estimates of regional capital stocks in a base year after allowing for depreciation. The base year estimates of stocks are problematic as are the time series deflators needed to express in constant prices, investment in a given region over time.

To get insight into the regional capital stocks in Israel, Beenstock, Felsenstein and Nadav Benzeev exploit the fact that the Israel Central Bureau of Statistics publishes regional data on completions in square meters for non-residential buildings. This is a direct method for estimating stocks for plants and overcomes the problem of regional deflators. This is made possible by the fact that the data are measured by quantity rather than price: the problem of regional deflators does not arise. They show that a process of capital deepening has been sigma-convergent since 1985, but was reversed over time as capital stocks and capital-labor ratios in the richer center have been catching up with their counterparts in the poorer periphery, mainly because of policy initiatives. 


\section{Structural equation modeling}

Structural equation models with latent variables (usually denoted LISREL models) have been used in the social sciences for some 40 years. This type of model was introduced by Jöreskog (1970) and further developed by, among others, Jöreskog and Goldberger (1975) and Jöreskog (1977, 1981). Moreover, the Lisrel program (Jöreskog, Sörbom 1996) and Mx (Neale et al. 2003) have been introduced to estimate and test structural equation models. Typical for structural equation models with latent variables is the possibility to include both latent and observable variables into one model framework. Whereas the latter (e.g., age, sex) possess direct empirical meanings derived from experience, latent variables (e.g., socioeconomic status) can only be measured by observables (e.g., socioeconomic status is measured by observables such as income, education and profession). To simultaneously analyze both latent and observable variables in one framework, a structural equation model is made up of a measurement model that represents the relationships between the latent variables and their observable indicators and a structural model that represents the relationships among the latent variables. Folmer and Oud (2008) and Folmer (2009) point out that the use of structural equation models has the following major advantages: a closer correspondence between theory (specified in terms of latent variables) and empirics; mitigation of the impacts of multicollinearity and mitigation of attenuation, i.e., biasing of a coefficient toward zero due to measurement errors in the explanatory variables.

The use of structural equation models in regional science (and economics) is limited (for an example, see Folmer 1986). However, recently structural equation models have been suggested to regional science, among others to model spatial dependence and in the context of continuous time modeling. Folmer and Oud (2008) propose the use of latent variables to represent spatial dependence and spatial spillover effects of which the observed spatially lagged variables are indicators. They show that the latent variables approach produces estimates that are in line with the estimates obtained by means of conventional methods. Moreover, they argue that compared to the classical Wy or Wx based approaches the structural equation approach allows incorporation of more information, to test more hypotheses on spatial dependence and offers more flexibility. However, they also strongly argue that further research, especially Monte Carlo simulation, is needed. Oud et al. (2010) apply structural equation modeling in the context of spatial-dependence continuous time modeling to take measurement errors into account for reducing attentuation.

The next paper in the issue is by Liu, Oud and one of the editors (Folmer). It is a methodological paper that compares by means of simulation two different methods of accounting for spatial autocorrelation: the classical spatial autoregressive model and the structural equations model with latent variables. Based on Anselin's Columbus, Ohio, crime data set, the simulation results show that the misspecified latent variables approach slightly trails the correctly specified classical approach in terms of bias and root mean squared error (RMSE).

In another paper, Liu and Noback apply the structural equation approach to study the determinants of female labor participation based on a sample of 278 municipalities in the Netherlands. They show that female participation is positively influenced by the 
added worker effect and negatively by the discouraged worker effect. The results show a negative impact of demographic pressure and a positive impact of socioeconomic status and a female-dominated sector structure.

Open Access This article is distributed under the terms of the Creative Commons Attribution Noncommercial License which permits any noncommercial use, distribution, and reproduction in any medium, provided the original author(s) and source are credited.

\section{References}

Folmer H (1986) Regional economic policy. Measurement of its effects. Martinus Nijhoff Publishers, Dordrecht

Folmer H, Oud J (2008) How to get rid of W: a latent variables approach to modelling spatially lagged variables. Environ Plan A 40:2526-2538

Folmer H (2009) Why sociology is better conditioned to explain economic behavior than economics. Kyklos $62(2): 258-274$

Greene WH (2004) Econometric analysis. Prentice Hall, Upper Saddle River

Jöreskog KG (1970) A general method for analysis of covariance structures. Biometrika 57:239-251

Jöreskog KG, Goldberger AS (1975) Estimation of a model with multiple indicators and multiple causes of a single latent variable. J Am Stat Assoc 70:631-639

Jöreskog KG (1977) Structural equation models in the social sciences: specification, estimation and testing. In: Krishnaiah PR (ed) Applications of statistics. North Holland, Amsterdam

Jöreskog KG (1981) Basic issues in the application of LISREL. Data, vol 1. Scientific Software International, Chicago, pp 1-6

Jöreskog KG, Sörbom D (1996) LISREL8: user's reference guide. Scientific Software International, Chicago

Kuhn TS (1962) The structure of scientific revolutions, 1st edn. University of Chicago, Chicago

Neale MC, Broker SM, Xie G, Maes HH (2003) Mx: Statistical modeling, 6th edn. Department of Psychiatry, Richmond

Oud J, Folmer H, Patuelli R, Nijkamp P (2010) A spatial-dependece continuous time model for regional unemployment change in Germany. Paper under revision at Geographical Analysis 